\title{
Mcl-1 downregulation sensitizes glioma to bortezomib-induced apoptosis
}

\author{
YANG ZHANG ${ }^{1}$, XIAOBO ZHU ${ }^{1}, \mathrm{KUN} \mathrm{HOU}^{1}$, JINCHUAN ZHAO ${ }^{1}$, ZHIGUO HAN $^{3}$ and XIAONA ZHANG ${ }^{2}$ \\ Departments of ${ }^{1}$ Neurosurgery and ${ }^{2}$ Anesthesiology, The First Affiliated Hospital of Jilin University, Changchun, Jilin; \\ ${ }^{3}$ Department of Neurosurgery, The Traditional Chinese Medical Hospital of Gongzhuling, Gongzhuling, Jilin, P.R. China
}

Received December 18, 2014; Accepted February 10, 2015

DOI: 10.3892/or.2015.3875

\begin{abstract}
Glioma is the most aggressive form of primary brain tumor, with dismal patient outcome and no effective therapeutic approaches available. Targeting the ubiquitinproteasome pathway has recently emerged as a potent rational anticancer strategy. Bortezomib, a specific proteasome inhibitor, has been approved for the treatment of relapsed or refractory multiple myeloma and other hematological malignancies as a single agent or as part of a combination therapy. However, bortezomib alone or in combination showed only minimal effects in the treatment of solid tumors. Myeloid cell leukemia-1 (Mcl-1) is an anti-apoptotic protein which protects tumor cells against spontaneous and chemotherapy-induced apoptosis. In multiple myeloma, specific downregulation of Mcl-1 induces apoptosis. Furthermore, previous studies demonstrated that proteasome inhibitors induce Mcl-1 accumulation that, in turn, slows down their pro-apoptotic effects, and the cell survival in multiple myeloma is highly dependent on Mcl-1. In the present study, we investigated the role of Mcl-1 downregulation in bortezomib-induced apoptosis in gliomas. We observed that bortezomib triggers caspase- 3 and PARP activation, upregulates cytochrome $c$ expression and induces apoptosis. Furthermore, we demonstrated that effective targeting of Mcl-1 in glioma cells by gene silencing technology augments the glioma cell sensitivity to bortezomib-induced apoptosis. In conclusion, the present study demonstrates that Mcl-1 plays a critical role in bortezomib-induced apoptosis. Mcl-1 inhibitor in combination with bortezomib present a promising novel strategy to trigger cell death pathways in the treatment of gliomas.
\end{abstract}

Correspondence to: Dr Xiaona Zhang, Department of Anesthesiology, The First Affiliated Hospital of Jilin University, Changchun, 71 Xinmin Avenue, Changchun, Jilin 130021, P.R. China

E-mail:xnzjlu@163.com

Key words: apoptosis, proteasome inhibitors, bortezomib, Mcl-1, glioma

\section{Introduction}

The proteasome is critical for the maintenance of homeostasis of the majority of intracellular proteins and is considered as a promising target for anticancer therapy. Bortezomib is the first proteasome inhibitor used for the treatment of relapsed or refractory multiple myeloma (1-3). In vitro, the drug is active against a wide variety of tumor cell types such as non-Hodgkin's lymphoma, mantle cell lymphoma and non-small cell lung cancer (4-7). Bortezomib has an acceptable toxicity profile and has shown clinical benefits, either alone or as part of a combination therapy, in induction of chemo/radio-sensitization or by overcoming drug resistance $(6,8)$. It was been proven that bortezomib is associated with apoptosis through upregulation of the pro-apoptotic proteins and downregulation of the anti-apoptotic factors. The latter includes the Bcl-2 subfamily proteins Bcl-xL, Bcl-2 and Mcl-1 (9-12).

Mcl-1 is a short-lived protein which opposes several apoptotic stimuli. These features distinguish it from other anti-apoptotic Bcl-2 members (13). Previous studies demonstrated that Mcl-1 is the essential survival protein in multiple myeloma and can be accumulated as a result of treatment with bortezomib (14). Furthermore, RNA interference mediates Mcl-1 downregulation and sensitizes human myeloma cell line to bortezomib, highlighting the role of this protein in bortezomib-induced apoptosis (1).

Gliomas are the most common and highly invasive primary brain tumors in humans. Despite some recent advances in surgical, radiation and chemotherapy approaches, the prognosis remains poor (15). Glioma cells display extreme resistance to apoptotic stimuli which contributes to the limited effectiveness of current therapies and the difficulty in developing new efficient treatment regiments $(15,16)$. This resistance may be due to the overexpression of anti-apoptotic Bcl-2-like proteins, such as Mcl-1, Bcl-2 and Bcl-xL $(16,17)$.

Bortezomib is successfully used for treating hematological malignancies. Its reported benefits in the treatment of solid tumors, however, are less than encouraging (18-22). Resistance to bortezomib in solid tumors further stimulates development of novel proteasome inhibitors, which would act differently from bortezomib, as well as novel natural compounds with proteasome-inhibitory activity that could be used as chemo/ radio-sensitizers. Current research efforts in solid tumors are 
now focused on the use of bortezomib in combination with other pro-apoptotic agents $(1,8)$.

In the present study, we examined the effect of Mcl-1 and/or the proteasome inhibitors on glioma cell growth and survival. We aimed to assess the specific role of Mcl-1 in the response to bortezomib.

\section{Materials and methods}

Cell lines and reagents. The glioblastoma cell lines U251 and U87 were purchased from the Chinese Academy of Medical Sciences (CAMS) and were grown as a monolayer in Dulbecco's modified Eagle's medium (DMEM) with $10 \%$ heat-inactivated fetal calf serum, $100 \mathrm{U} / \mathrm{ml}$ penicillin and $100 \mathrm{mg} / \mathrm{ml}$ streptomycin and were maintained in a humidified incubator at $37^{\circ} \mathrm{C}$ and $5 \% \mathrm{CO}_{2}$. Bortezomib was obtained from Sigma (St. Louis, MO, USA). Antibodies against caspase-3 (human mAb), PARP (F7 human mAb), cytochrome $c$ (human polyclonal), and Mcl-1 (S19, human mAb) were from Santa Cruz Biotechnology (Santa Cruz, CA, USA).

MTT cell viability assay. U87 and U251 cells were plated on 96-well plates $(2,000$ cells/well) and treated with bortezomib (100 ng/ml; Sigma) for $24 \mathrm{~h}$. Following the treatment, thiazolyl blue tetrazolium bromide (MTT, $5 \mathrm{mg} / \mathrm{ml}$; Sigma) was added to each well, and the cells were incubated in the dark at $37^{\circ} \mathrm{C}$. MTT produces a yellowish solution that is converted to dark blue, water-insoluble MTT formazan by mitochondrial dehydrogenases of the living cells. After $4 \mathrm{~h}$, the medium was aspirated and the dark blue crystals were dissolved in dimethyl sulfoxide (DMSO) $(150 \mu \mathrm{l})$ and incubated for $10 \mathrm{~min}$. The absorbance of each sample was measured at 490 or $570 \mathrm{~nm}$ using a microplate reader (GENios; Tecan Schweiz AG, Männedorf, Switzerland). The absorbance was proportional to the number of the viable cells and was expressed relative to the untreated negative control cultures.

Western blot analysis. Western blot analysis was performed on lysates prepared from U251 and U87 cells treated as indicated. The cells were homogenized in the lysis buffer containing $0.5 \mathrm{mM}$ Tris-Cl (pH 6.8), $2 \%$ SDS (w/v), $10 \%$ glycerin (w/v) and protease inhibitor cocktails (Sigma-Aldrich, Dublin, Ireland). After determining the protein concentration of the samples using the BCA protein assay (Pierce, Rockford, IL, USA), $20 \mu \mathrm{g}$ samples were boiled in gel-loading buffer and separated on 10-15\% SDS-PAGE. Proteins were transferred to the nitrocellulose membranes and analyzed following the standard procedures. The membranes were incubated with anti-human Mcl-1, anti-caspase-3 antibodies and anti-human PARP, anti-human cytochrome $c$ (Sigma) overnight at $4^{\circ} \mathrm{C}$. The membranes were then incubated with horseradish peroxidaseconjugated secondary antibodies (Jackson ImmunoResearch Laboratories, Plymouth, PA, USA), and protein bands were visualized using enhanced chemiluminescence detection (Pierce). Images were captured using Fujifilm LAS-3000 (Fujifilm, Sheffield, UK).

Flow cytometry and analysis of apoptosis via Annexin V/propidium iodide staining. U251 and U87 cells were plated in 24-well plates $(15,000$ cells/well) and were treated with bortezomib for $48 \mathrm{~h}$. Following the treatment, the monolayer cells were harvested with trypsin-EDTA and washed with PBS. Cells were then incubated at room temperature in binding buffer (10 mM HEPES, $135 \mathrm{mM} \mathrm{NaCl}, 5 \mathrm{mM} \mathrm{CaCl}_{2}$ ) which contained Annexin V-FITC conjugate $(1 \mu \mathrm{l} / \mathrm{ml}$; BioVision, Mountain View, CA, USA) and propidium iodide (PI; $1 \mu \mathrm{l} / \mathrm{ml}$; BioVision) for $15 \mathrm{~min}$. Excitation of Annexin V-FITC was done with a $488 \mathrm{~nm}$ laser, and fluorescence emission was collected in the FL1 channel through a 520-nm band pass filter. PI was excited with a 488-nm laser and fluorescence emission was collected in the FL3 channel through a 620-nm long pass filter. Gated cells $\left(1 \times 10^{4}\right)$ were acquired for each sample, and flow cytometric analysis was done on a FACSCalibur flow cytometer (BD Biosciences, San Jose, CA, USA) using the CellQuest software (BD Biosciences). Each analysis was performed using at least 10,000 events.

Mcl-1 RNA interference assay. The sequence of the small interfering RNA (siRNA) used to silence $\mathrm{Mcl}-1$ gene (Mcl-1 siRNA) was 5'-GUAAUUAUUGACACAUUUCUU-3'. Both siRNA and negative control siRNA were synthesized by Ambion (Life Technologies, Carlsbad, CA, USA). U87 and U251 cells were electroporated using Amaxa Nucleofector system (Lonza, Walkersville, MD, USA) according to the manufacturer's instructions. Briefly, 5x106 U87 and U251 cells were re-suspended in $100 \mu \mathrm{l}$ of $\mathrm{R}$ nucleofector solution containing $10 \mu \mathrm{M}$ siRNA and electroporated using T01 nucleofector program. Cells were transferred to culture plates and cultured at $5 \times 10^{5}$ cells $/ \mathrm{ml}$ for $2 \mathrm{~h}$ before incubation with bortezomib.

Statistical analysis. All data are given as the mean \pm SD. N is the number of the samples. Western blot data are expressed relative to the control, assigning a value of 1 to the control group baseline mean. Data were analyzed using Student's t-test or 2-way ANOVA by SPSS 17.0 software as appropriate. $\mathrm{P}$-value $<0.05$ was considered as a significant difference between the data sets.

\section{Results}

Bortezomib can reduce the viability of U251 and U87 glioma cells in a dose-dependent manner. Previous research has shown that proteasome inhibitor bortezomib can cause apoptosis in vitro in a variety of tumor cells, such as prostate, breast and colon cancer (4-7). Therefore, we first used the MTT method to determine the effects of bortezomib on the glioma cell viability. We chose two common glioma cell lines, U251 and U87, for our experiments. Cells were cultured with or without various doses of bortezomib for $24 \mathrm{~h}$. Bortezomib significantly reduced the survival rate of U251 and U87 cells in a dose-dependent manner (Fig. 1). The median inhibitory concentration $\left(\mathrm{IC}_{50}\right)$ of bortezomib for $\mathrm{U} 251$ and $\mathrm{U} 87$ cells was 25.52 and $29.37 \mathrm{nM}(\mathrm{n}=6 /$ cell line).

Bortezomib induces apoptosis in U251 and U87 glioma cells. Since the MTT results showed that bortezomib can reduce the U251 and U87 cell viability, we investigated the effect of bortezomib on apoptosis in glioma cells. We recorded the influence of different bortezomib concentration on the 

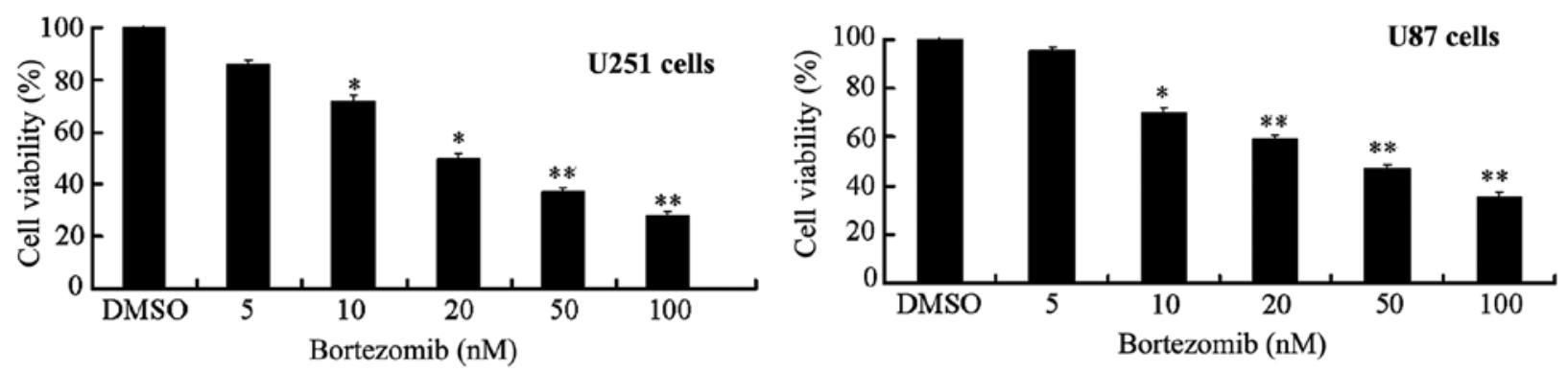

Figure 1. Bortezomib reduces cell viability in a dose-dependent manner. U87 and U251 cells were cultured in DMEM supplemented with $10 \%$ FBS in the presence of various doses of bortezomib. Cell viability was measured by an MTT assay at $24 \mathrm{~h}$ relative to the control. Values are the mean $\pm \mathrm{SD} ; \mathrm{n}=6 .{ }^{* * *} \mathrm{P}<0.05$ compared with the control group.

A
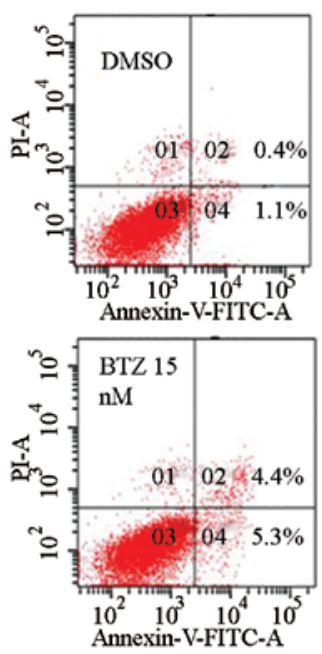

U251 cells
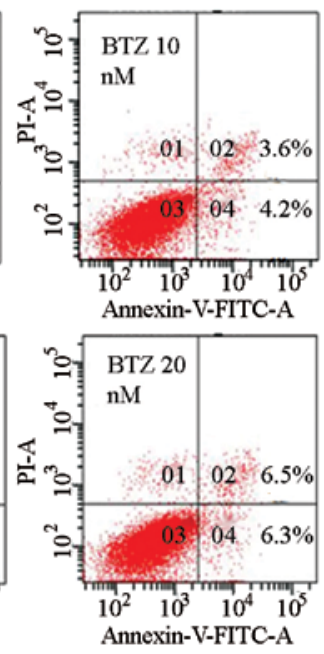

B

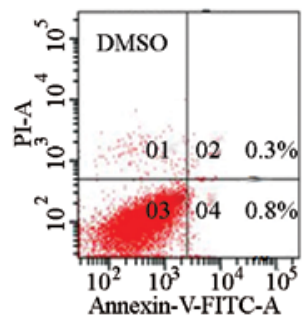

U87 cells

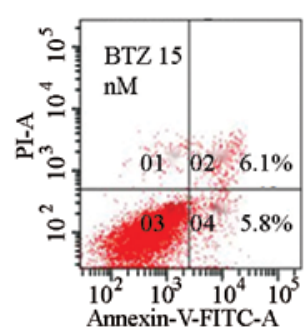

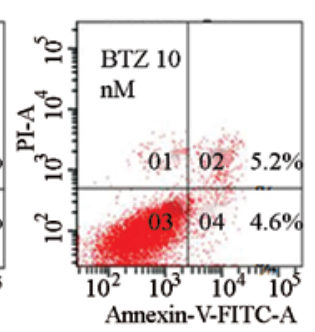

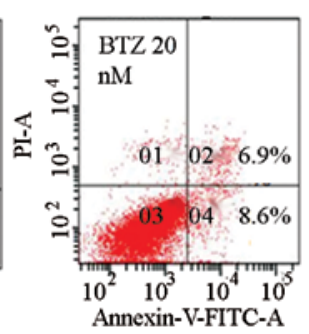

Figure 2. Bortezomib induces apoptosis in glioma cell lines. (A) The effect of bortezomib on U251 cell apoptosis, as assessed by flow cytometry. (B) The effect of bortezomib on U87 cell apoptosis, as assessed by flow cytometry. The percentage (\%) of cells in each fraction was determined by positivity for Annexin V and PI staining at the different doses of bortezomib.

apoptosis by Annexin V and PI double dye staining using flow cytometry. Different concentrations of bortezomib can cause apoptosis of U251 and U87 cells (Fig. 2). Bortezomib at concentration of 10-20 $\mathrm{nM}$ can induce apoptosis effectively in U87 and U251 cells, as established mainly through the detection of apoptosis-related proteins caspase-3 and PARP by western blot analysis.

Bortezomib triggers dose-dependent cleavage and activation of caspase-3, PARP activation and upregulation of the cytochrome c expression in U251 and U87 glioma cells. Several members of the Bcl-2 family are known to be targets for bortezomib. In order to further determine the effect of bortezomib on the apoptosis in the two glioma cell lines, we checked the expression levels of apoptosis-related proteins by using western blot analysis. Under normal circumstances, caspase-3 can exist in an inactive form. PARP, as a DNA repair enzyme, is also the substrate of caspase. After being cleaved, the activated form of caspase- 3 mediates cell apoptosis. Cytochrome $c$ is an important component in the mitochondrial apoptosis signaling pathways. Following the change of the mitochondrial membrane permeability, cytochrome $c$ which is located between the mitochondrial membrane and the outer membrane can be released into the cytoplasm and can trigger the apoptosis cascade. Bortezomib can significantly increase the level of the cleaved form of caspase-3, PARP and cytochrome $c$ expression in a dose-dependent manner (Fig. 3).

Bortezomib upregulates Mcl-1 while Mcl-1 siRNA downregulates the Mcl-1 expression. Studies have shown that anti-apoptotic protein Mcl-1 is degraded by the ubiquitinproteasome pathway. As a proteasome inhibitor, bortezomib can induce apoptosis in glioma cells. Using western blot analysis, we explored the effect of Mcl-1 on the apoptosis induced by bortezomib in two types of glioma cells, U251 and U87. Bortezomib increases the protein expression level of Mcl-1 in both cell lines (Fig. 4A). Furthermore, using siRNA technology, we checked the expression levels of Mcl-1 after siRNA transfection. As shown in Fig. 4B, 24 and $48 \mathrm{~h}$ after transfection of Mcl-1 siRNA plasmids, the Mcl-1 siRNA clearly inhibits the Mcl-1 expression in U251 and U87 cells.

Knocking down Mcl-1 expression increases glioma cell sensitivity to the inhibition of cell growth by bortezomib. To definitely establish the role of Mcl-1 in the bortezomibinduced apoptosis in glioma cells, we made use of RNA 
A

U251

Bortezomib (nM)
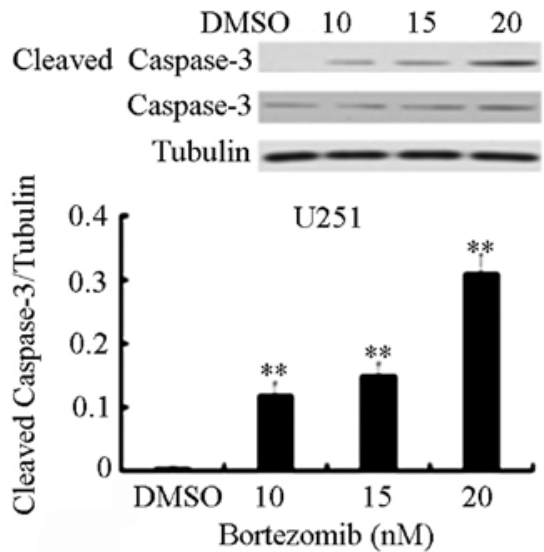

B U251 Bortezomib $(\mathrm{nM})$
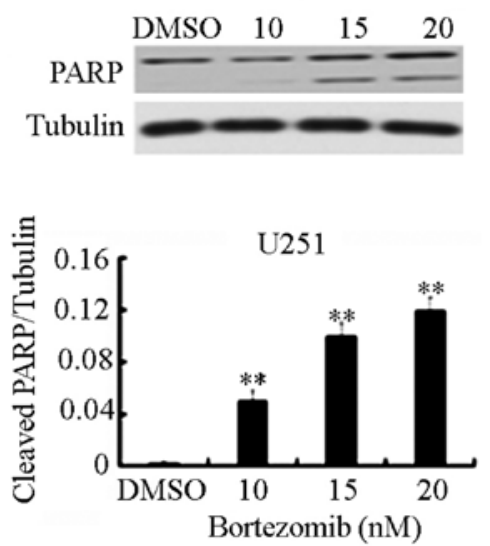

C U251

Bortezomib (nM)

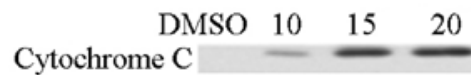

Tubulin

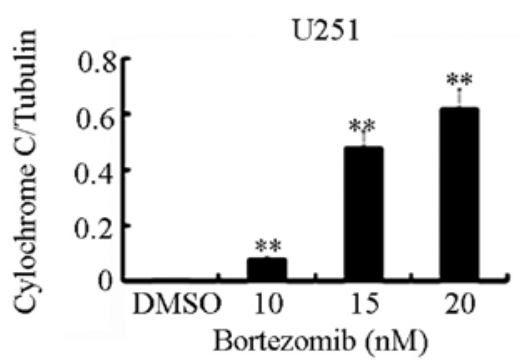

U87
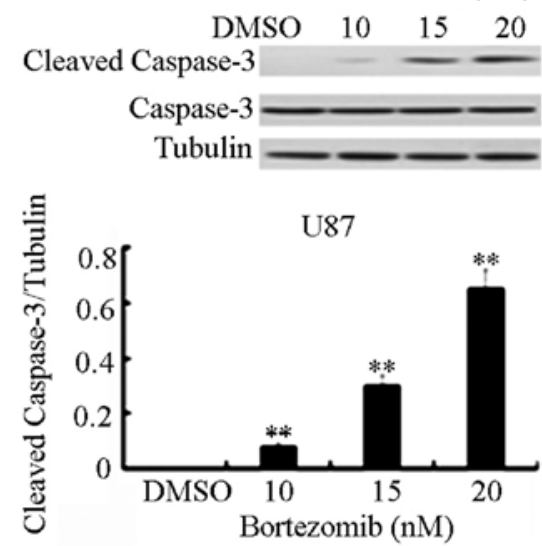

U87

Bortezomib (nM)

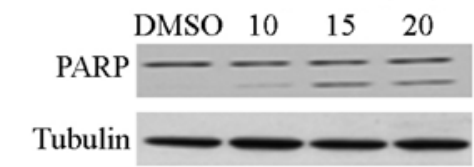

U87

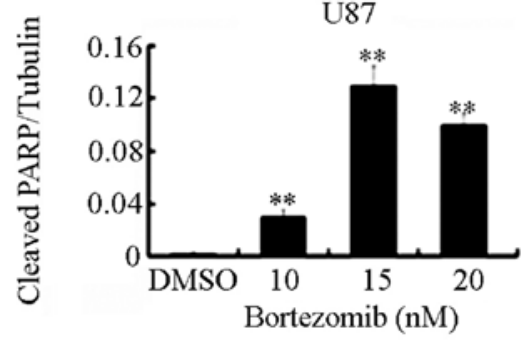

U87

Bortezomib (nM)
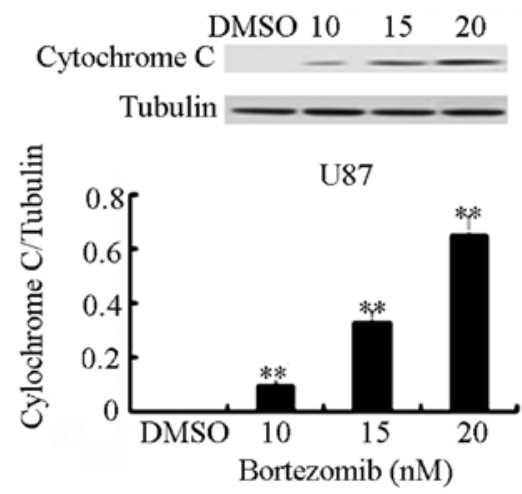

Figure 3. Bortezomib triggers a dose-dependent activation of caspase-3 and PARP and upregulates the cytochrome $c$ expression. The U87 and U251 cells were treated with 10,15 and $20 \mathrm{nM}$ bortezomib for $4 \mathrm{~h}$. Cell lysates were subjected to western blot analysis. Membranes were probed with the respective antibodies. Tubulin was used as a loading control. (A) The effect of bortezomib on the expressions of caspase-3 in U251 and U87 cells. (B) The effect of bortezomib on the expression of PARP in U251 and U87 cells. (C) The effect of bortezomib on the expression of cytochrome $c$ in U251 and U87 cells. Values are the mean \pm SD; $\mathrm{n}=3 .{ }^{* *} \mathrm{P}<0.01$ compared with the control group.

interference (RNAi) technology. We transfected U87 and U251 cells with Mcl-1 siRNA and control siRNA to evaluate the potential effects on the cell viability due to Mcl-1 downregulation. The MTT assay demonstrated that the combined treatment with bortezomib and Mcl-1 siRNA can significantly inhibit U251 and U87 cell viability. The inhibition of Mcl-1 expression can increase the sensitivity of both cell types to bortezomib (Fig. 5).
Knockdown of Mcl-1 augments apoptosis induced by bortezomib in U251 and U87 glioma cells. Based on previous experimental results which demonstrated that Mcl-1 siRNA can increase the inhibition of cell growth, we used siRNA to knock down Mcl-1 expression in order to determine whether Mcl-1 played an essential role in bortezomibinduced apoptosis. Using flow cytometry, we observed that Mcl-1 siRNA can significantly enhance bortezomib-induced 
A
U251

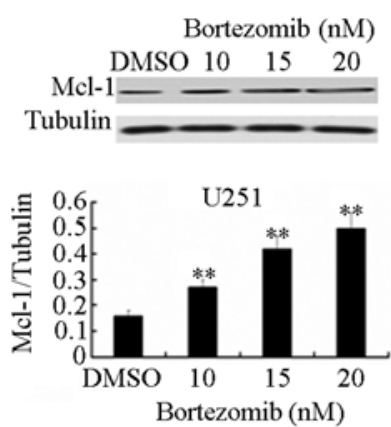

U87

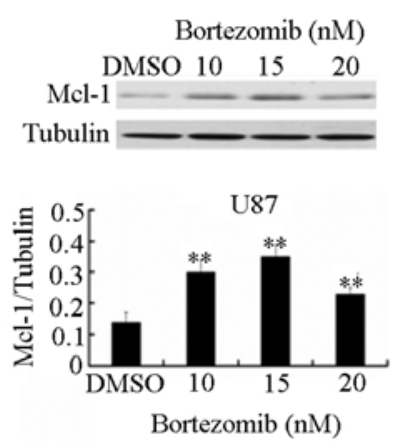

B $\mathbf{U} 251$

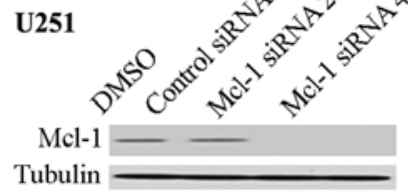

$\mathrm{U} 251$

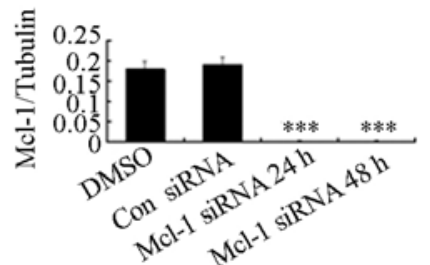

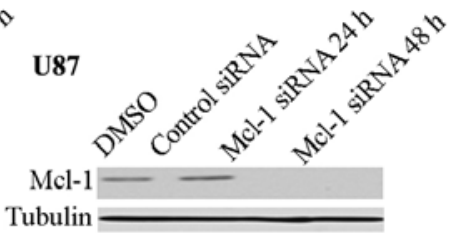

U87

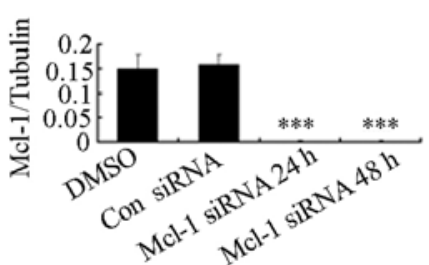

Figure 4. Bortezomib upregulates Mcl-1 protein, and Mcl-1 siRNA downregulates Mcl-1 expression. U251 and U87 cells were transfected with Mcl-1 siRNA or control siRNA. (A) The effect of bortezomib on the expressions of Mcl-1 in U251 and U87 cells. (B) The effect of Mcl-1 siRNA on the expressions of Mcl-1 in $\mathrm{U} 251$ and $\mathrm{U} 87$ cells. Values are the mean $\pm \mathrm{SD} ; \mathrm{n}=3 .{ }^{* *} \mathrm{P}<0.01$ compared with the control group.
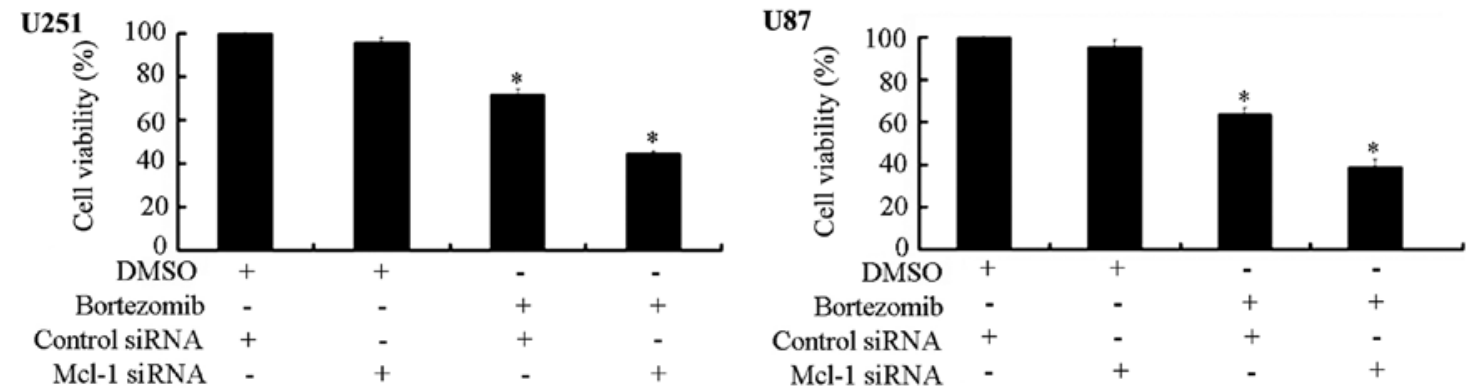

Figure 5. Knocking down Mcl-1 expression increases glioma cell sensitivity to the inhibition of cell growth in U251 and U87 cells. U251 and U87 cells were transfected with Mcl-1 siRNA or control siRNA. Two hours after transfection, U251 and U87 cells were treated with bortezomib (10 nM) for $72 \mathrm{~h}$. After treatment, the MTT assays were carried out to assess cell viability. Values are the mean $\pm \mathrm{SD} ; \mathrm{n}=3$. ${ }^{\prime} \mathrm{P}<0.05$ compared with the control group.

$\mathbf{A}$

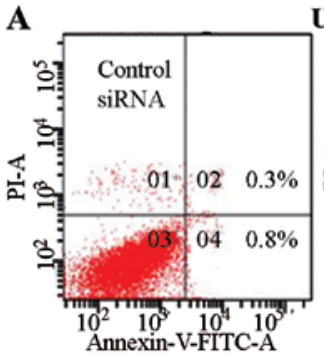

U251

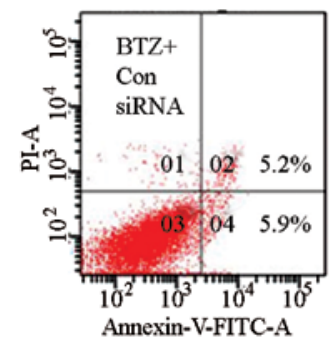

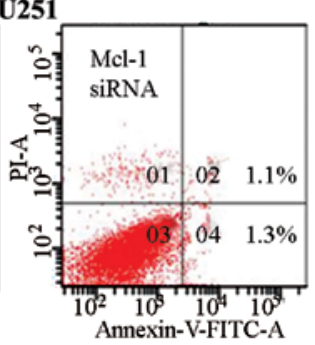

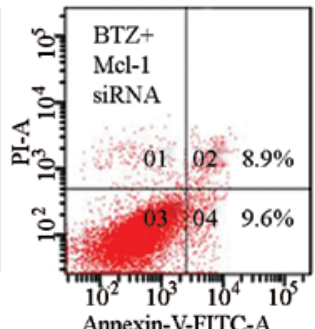

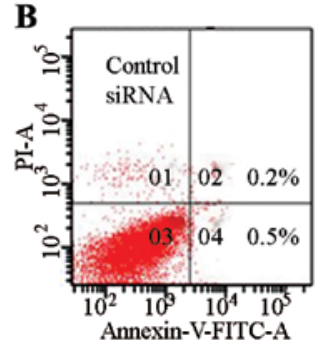
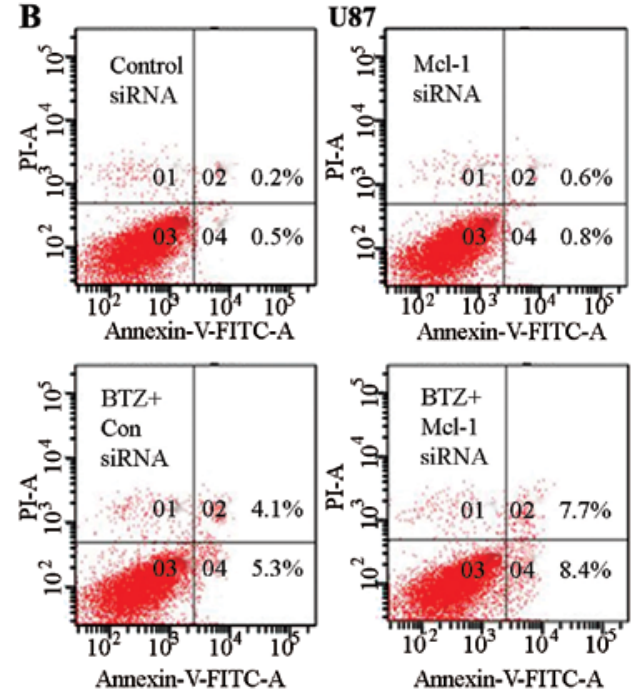

Figure 6. Knockdown of Mcl-1 augments apoptosis induced by bortezomib in U251 and U87 glioma cells. U251 and U87 cells were transfected with Mcl-1 siRNA or control siRNA. Two hours after transfection, U251 and U87 cells were treated with bortezomib (10 nM) for $24 \mathrm{~h}$. The induction of apoptosis was determined by Annexin V and PI staining using flow cytometry. The percentage (\%) of cells in each fraction was determined by positivity for Annexin V and PI staining at the different combination of bortezomib and siRNA treatment.

apoptosis compared with the control siRNA in U251 and U87 glioma cells (Fig. 6). We also checked the protein expression level of caspase-3 and PARP by western blot analysis. We found that Mcl-1 siRNA in combination with bortezomib 
A

$\mathbf{A}_{\mathbf{U} 251}$

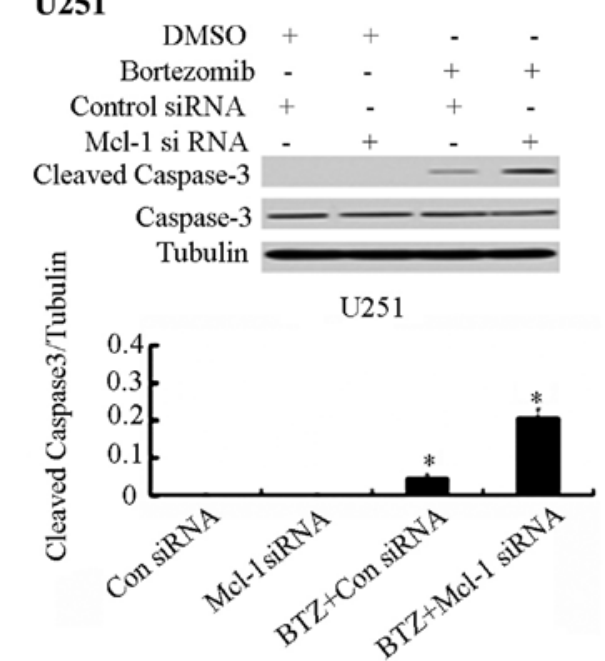

B

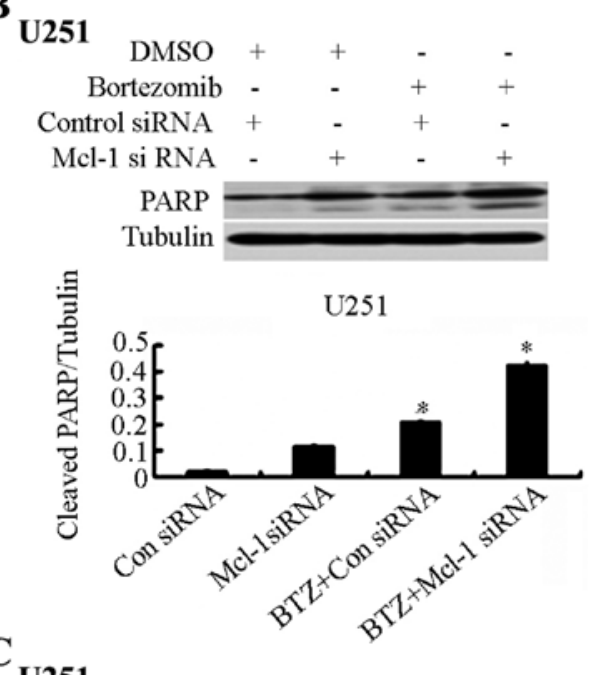

U251

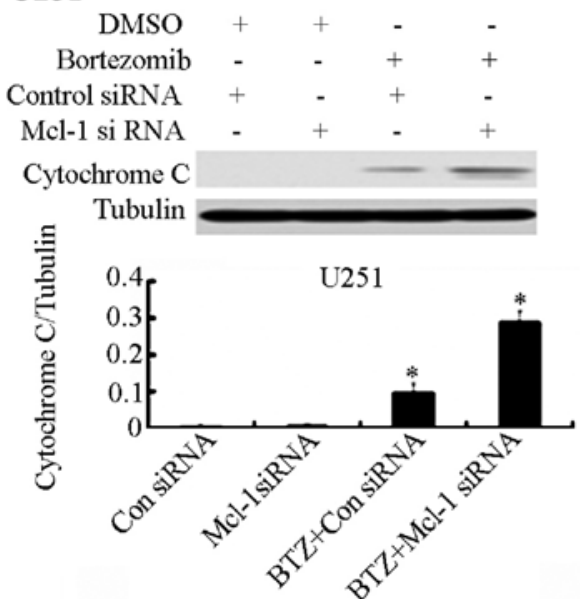

U87
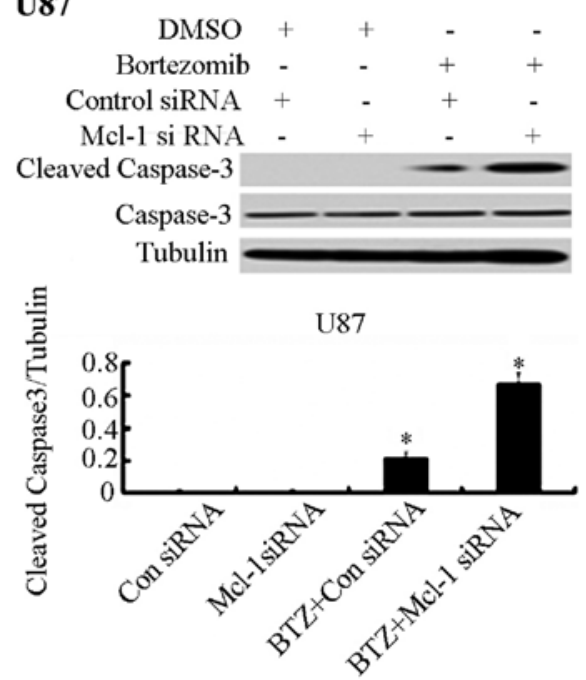

U87

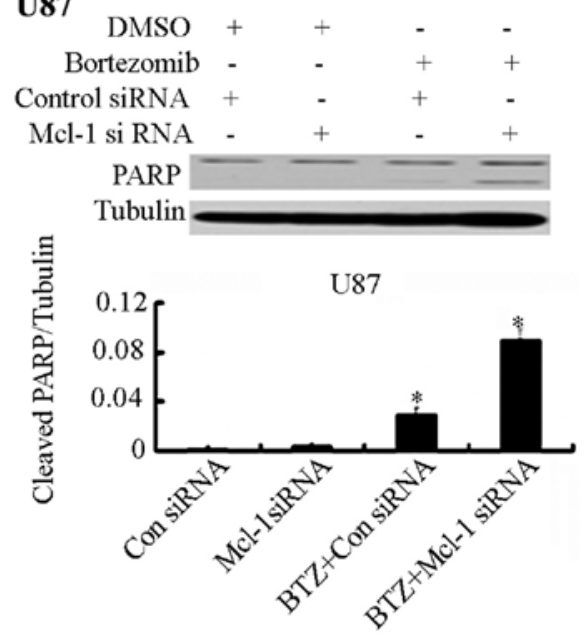

U87

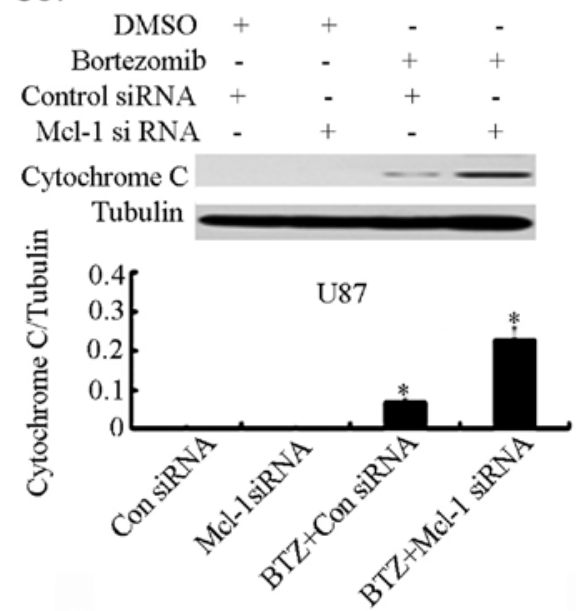

Figure 7. Altered expression of apoptosis-associated proteins in U251 and U87 cells following the treatment with bortezomib and Mcl-1 siRNA. U251 and U87 cells were transfected with Mcl-1 siRNA or control siRNA. Two hours after transfection, U251 and U87 cells were treated with bortezomib (10 nM) for 24 h. Western blot analysis of expression of the apoptosis-associated proteins was carried out on U251 and U87 cells. Tubulin was used as a loading control. (A) The effect of Mcl-1 siRNA on the expression of cleaved caspase-3 in U251 and U87 induced by bortezomib. (B) The effect of Mcl-1 siRNA on the expression of PARP in U251 and U87 induced by bortezomib. (C) The effect of Mcl-1 siRNA on the expression of cytochrome $c$ in U251 and U87 induced by bortezomib. Values are the mean $\pm \mathrm{SD} ; \mathrm{n}=3$. ${ }^{*} \mathrm{P}<0.05$ compared with the control group.

can significantly increase the expression of caspase-3 and PARP (Fig. 7A and B). Furthermore, the expression level of cytochrome $c$ was increased after the Mcl-1 siRNA treatment (Fig. 7C). 


\section{Discussion}

The ubiquitin-proteasome pathway represents the major pathway for intracellular protein degradation $(23,24)$. The $26 \mathrm{~S}$ proteasome is responsible for the degradation of $\sim 80 \%$ of all cellular proteins and plays an important role in the regulation of cell growth and survival (25-27). Inhibition of the proteasomal function in cancer cells would promote apoptosis and has been shown to induce pro-apoptotic ER stress in multiple myeloma (1), pancreatic (21), prostate cancer (18) and non-small cell lung carcinoma (7). Therefore, proteasome inhibitors represent a novel class of compounds with promising antitumor activity and potential of becoming a new important tool for the treatment of cancer. Bortezomib, the 26S proteasome inhibitor, is the first proteasome inhibitor to enter clinical trials (2), and has demonstrated encouraging efficacy against multiple myeloma, where it has become an approved therapy. In addition, bortezomib often induces apoptosis on its own or when used together with other novel therapeutic or chemotherapeutic agents (6-8). After the major success achieved with bortezomib in hematological malignancies, its effect on solid tumors was also investigated, but the results reported so far were significantly less impressive (28). In the present study, we provided novel information on the cellular effects of bortezomib and Mcl-1 in glioma cell lines.

Bortezomib has been observed to target many molecules that are associated with tumor progression and treatment resistance, such as nuclear factor- $\kappa \mathrm{B}(\mathrm{NF}-\kappa \mathrm{B})$, pro-apoptotic and anti-apoptotic Bcl-2 family proteins and p53 $(1,3)$. One major mechanism of bortezomib associated with its anticancer activity has been attributed to the inhibition of IкB degradation, which leads to the suppression of the NF- $\kappa B$ signaling pathway and results in the downregulation of its anti-apoptotic target genes $(3,29)$. For example, bortezomib can decrease the increment rate of multiple myeloma cells more than twice by reducing the activity of NF- $\mathrm{KB}$ compared with chemotherapysensitive cells. Bortezomib can enhance radiation sensitivity in colon cancer cells when NF- $\mathrm{KB}$ activation is inhibited. Another important mechanism of this drug involves upregulation of Noxa, a pro-apoptotic protein which may interact with the anti-apoptotic proteins of the Bcl-2 subfamily, Bcl-xL and Bcl-2 (1,30). Bortezomib-mediated apoptosis is accompanied by induction of c-Jun $\mathrm{N}$-terminal kinase, generation of reactive oxygen species, release of cytochrome $c$ (the second mitochondria-derived activator of caspases and apoptosis-inducing factor), and activation of the intrinsic caspase- 9 and extrinsic caspase-8 pathways. In non-small cell lung cancer $\mathrm{H} 460$ cells, bortezomib can trigger cell arrest in the G2-M phase and thus initiate apoptosis (31). Cell cycle arrest can increase the phosphorylation and degradation of $\mathrm{Bcl}-2$ and the accumulation of cyclins A and B1 (32). It is very important to further explore the different mechanisms of bortezomib in the induction of apoptosis in different tumor cells.

The pivotal role Mcl-1 plays in protecting cancer cells from apoptosis is well documented $(33,34)$. In glioma cells, the downregulation of Mcl-1 through the use of siRNA has been proven to significantly decrease cell proliferation and increase apoptosis (35). Since upregulation of anti-apoptotic factors by bortezomib could negatively affect its antitumor effect (4), we explored the implication of using the RNAi technology on Mcl-1 level in glioma cells. Initially, we observed Mcl-1 downregulation following Mcl-1 siRNA treatment. However, this downregulation was not sufficient to induce a significant level of apoptosis due, in part, to lack of caspase-3 activation in these cells. Compared with the limited effects observed with the single agent therapy, addition of bortezomib together with Mcl-1 inhibitor triggered the release of the pro-apoptotic protein cytochrome $c$ into the cytosolic fraction and accumulation of increased levels of cleaved caspases and PARP, hallmarks of apoptosis (36). We have previously shown that Mcl-1 downregulation is important to make multiple myeloma cells susceptible to BH3-only proteins and therefore to mitochondrial disruption $(37,38)$. As a result of Mcl-1 downregulation following siRNA treatment, BH3-only proteins may block the anti-apoptotic effect of the members of the Bcl-2 superfamily (Bcl-2, Bcl-xL or Mcl-1), and/or induce $\mathrm{Bax} / \mathrm{Bak}$ conformational change. Activated Bax and Bak form pores in the outer mitochondrial membrane, resulting in the release of cytochrome $c$ and activators of caspases from the intermembrane space into the cytosol (37-41). Noxa is capable of displacing the activator BH3-only protein, Bim, and the pro-apoptotic protein, Bak, from Mcl-1/Bim and Mcl-1/Bak complexes, respectively, thereby triggering mitochondrial dysfunction, caspase activation and, ultimately, apoptosis $(42,43)$. Recently, Han et al $(40)$ have demonstrated that Mcl-1 is a direct substrate for caspase- 8 , and that loss of Mcl-1 generates Mcl-1-free Bim that is involved in the apoptotic events. This observation suggests the potential existence of novel cross-talk mechanism between the extrinsic and the intrinsic apoptotic pathways in the initiation of apoptosis.

Collectively, the present study demonstrates the efficient induction of apoptosis by proteasome inhibitor bortezomib in the glioma cell lines and provides novel evidence that a combinational therapeutic treatment regime modulating the Mcl-1 expression levels may be an efficacious approach to sensitize glioma to the apoptosis-inducing effects of bortezomib. Bortezomib can inhibit the expression of Mcl-1 and increase the bortezomib sensitivity in the glioma U251 and U87 cells. The combined use of bortezomib and Mcl-1 inhibitor can effectively inhibit the proliferation of glioma cells. Elucidation of the pathways of cell death induced by Mcl-1 downregulation in combination with bortezomib treatment may help to identify key molecular targets that govern the viability of glioma cells. These targets could be further manipulated to provide antitumor effects and warrant further investigation.

\section{References}

1. Gomez-Bougie P, Wuillème-Toumi S, Ménoret E, Trichet V, Robillard N, Philippe M, Bataille R and Amiot M: Noxa up-regulation and Mcl-1 cleavage are associated to apoptosis induction by bortezomib in multiple myeloma. Cancer Res 67: 5418-5424, 2007.

2. Chen D, Frezza M, Schmitt S, Kanwar J and Dou QP: Bortezomib as the first proteasome inhibitor anticancer drug: Current status and future perspectives. Curr Cancer Drug Targets 11: 239-253, 2011.

3. Lesinski GB, Raig ET, Guenterberg K, Brown L, Go MR, Shah NN, Lewis A, Quimper M, Hade E, Young G, et al: IFN-alpha and bortezomib overcome Bcl-2 and Mcl-1 overexpression in melanoma cells by stimulating the extrinsic pathway of apoptosis. Cancer Res 68: 8351-8360, 2008. 
4. Kane RC, Dagher R, Farrell A, Ko CW, Sridhara R, Justice R and Pazdur R: Bortezomib for the treatment of mantle cell lymphoma. Clin Cancer Res 13: 5291-5294, 2007.

5. Orlowski RZ, Eswara JR, Lafond-Walker A, Grever MR, Orlowski $\mathrm{M}$ and Dang CV: Tumor growth inhibition induced in a murine model of human Burkitt's lymphoma by a proteasome inhibitor. Cancer Res 58: 4342-4348, 1998.

6. Fisher RI, Bernstein SH, Kahl BS, Djulbegovic B, Robertson MJ, de Vos S, Epner E, Krishnan A, Leonard JP, Lonial S, et al: Multicenter phase II study of bortezomib in patients with relapsed or refractory mantle cell lymphoma. J Clin Oncol 24: 4867-4874, 2006.

7. Fanucchi MP, Fossella FV, Belt R, Natale R, Fidias P, Carbone DP, Govindan R, Raez LE, Robert F, Ribeiro M, et al Randomized phase II study of bortezomib alone and bortezomib in combination with docetaxel in previously treated advanced non-small-cell lung cancer. J Clin Oncol 24: 5025-5033, 2006.

8. Berenson JR, Yang HH, Sadler K, Jarutirasarn SG, Vescio RA, Mapes R, Purner M, Lee SP, Wilson J, Morrison B, et al: Phase I/II trial assessing bortezomib and melphalan combination therapy for the treatment of patients with relapsed or refractory multiple myeloma. J Clin Oncol 24: 937-944, 2006.

9. Strauss SJ, Higginbottom K, Juliger S, Maharaj L, Allen P, Schenkein D, Lister TA and Joel SP: The proteasome inhibitor bortezomib acts independently of p53 and induces cell death via apoptosis and mitotic catastrophe in B-cell lymphoma cell lines. Cancer Res 67: 2783-2790, 2007.

10. Fribley A and Wang CY: Proteasome inhibitor induces apoptosis through induction of endoplasmic reticulum stress. Cancer Biol Ther 5: 745-748, 2006.

11. Lioni M, Noma K, Snyder A, Klein-Szanto A, Diehl JA, Rustgi AK, Herlyn M and Smalley KS: Bortezomib induces apoptosis in esophageal squamous cell carcinoma cells through activation of the $\mathrm{p} 38$ mitogen-activated protein kinase pathway. Cancer Ther 7: 2866-2875, 2008.

12. Zhang L,Lopez H, George NM,Liu X,Pang X and Luo X: Selective involvement of BH3-only proteins and differential targets of Noxa in diverse apoptotic pathways. Cell Death Differ 18: 864-873, 2011.

13. Kozopas KM, Yang T, Buchan HL, Zhou P and Craig RW: MCL1, a gene expressed in programmed myeloid cell differentiation, has sequence similarity to BCL2. Proc Natl Acad Sci USA 90 3516-3520, 1993.

14. Zhang B, Gojo I and Fenton RG: Myeloid cell factor-1 is a critical survival factor for multiple myeloma. Blood 99: 1885-1893, 2002.

15. Eramo A, Ricci-Vitiani L, Zeuner A, Pallini R, Lotti F, Sette G, Pilozzi E, Larocca LM, Peschle C and De Maria R: Chemotherapy resistance of glioblastoma stem cells. Cell Death Differ 13: 1238-1241, 2006.

16. Strik H, Deininger M, Streffer J, Grote E, Wickboldt J, Dichgans J, Weller M and Meyermann R: BCL-2 family protein expression in initial and recurrent glioblastomas: modulation by radiochemotherapy. J Neurol Neurosurg Psychiatry 67: 763-768, 1999.

17. Stegh AH, Kim H, Bachoo RM, Forloney KL, Zhang J, Schulze H, Park K, Hannon GJ, Yuan J, Louis DN, et al: Bcl2L12 inhibits post-mitochondrial apoptosis signaling in glioblastoma. Genes Dev 2: 98-111, 2007.

18. Papandreou CN, Daliani DD, Nix D, Yang H, Madden T, Wang X, Pien CS, Millikan RE, Tu SM, Pagliaro L, et al: Phase I trial of the proteasome inhibitor bortezomib in patients with advanced solid tumors with observations in androgen-independent prostate cancer. J Clin Oncol 22: 2108-2121, 2004.

19. Frankel A, Man S, Elliott P, Adams J and Kerbel RS: Lack of multicellular drug resistance observed in human ovarian and prostate carcinoma treated with the proteasome inhibitor PS-341. Clin Cancer Res 6: 3719-3728, 2000.

20. Sunwoo JB, Chen Z, Dong G, Yeh N, Crowl Bancroft C, Sausville E, Adams J, Elliott P and Van Waes C: Novel proteasome inhibitor PS-341 inhibits activation of nuclear factor-kappa B cell survival, tumor growth, and angiogenesis in squamous cell carcinoma. Clin Cancer Res 7: 1419-1428, 2001.

21. Nawrocki ST, Bruns CJ, Harbison MT, Bold RJ, Gotsch BS Abbruzzese JL, Elliott P, Adams J and McConkey DJ: Effects of the proteasome inhibitor PS-341 on apoptosis and angiogenesis in orthotopic human pancreatic tumor xenografts. Mol Cancer Ther 1: 1243-1253, 2002.

22. Kukreja A,Hutchinson A, Mazumder A, et al: Bortezomib disrupts tumour-dendritic cell interactions in myeloma and lymphoma: therapeutic implications. Br J Haematol 136: 106-110, 2007.
23. Adams J: The proteasome: a suitable antineoplastic target. Nat Rev Cancer 4: 349-360, 2004.

24. Ciechanover A: The ubiquitin-proteasome proteolytic pathway. Cell 79: 13-21, 1994.

25. Hochstrasser M: Ubiquitin, proteasomes, and the regulation of intracellular protein degradation. Curr Opin Cell Biol 7: 215-223, 1995.

26. Ciechanover A: The ubiquitin-proteasome pathway: On protein death and cell life. EMBO J 17: 7151-7160, 1998.

27. Peters JM, Cejka Z, Harris JR, Kleinschmidt JA and Baumeister W: Structural features of the $26 \mathrm{~S}$ proteasome complex. J Mol Biol 234: 932-937, 1993.

28. Engel RH, Brown JA, Von Roenn JH, O'Regan RM, Bergan R, Badve S, Rademaker A and Gradishar WJ: A phase II study of single agent bortezomib in patients with metastatic breast cancer: a single institution experience. Cancer Invest 25: 733-737, 2007.

29. Berenson JR, Ma HM and Vescio R: The role of nuclear factorkappaB in the biology and treatment of multiple myeloma. Semin Oncol 28: 626-633, 2001

30. Qin JZ, Ziffra J, Stennett L, Bodner B, Bonish BK, Chaturvedi V, Bennett F, Pollock PM, Trent JM, Hendrix MJ, et al: Proteasome inhibitors trigger NOXA-mediated apoptosis in melanoma and myeloma cells. Cancer Res 65: 6282-6293, 2005

31. Domina AM, Smith JH and Craig RW: Myeloid cell leukemia 1 is phosphorylated through two distinct pathways, one associated with extracellular signal-regulated kinase activation and the other with $\mathrm{G} 2 / \mathrm{M}$ accumulation or protein phosphatase $1 / 2 \mathrm{~A}$ inhibition. J Biol Chem 275: 21688-21694, 2000.

32. Ma MH, Yang HH, Parker K, Manyak S, Friedman JM, Altamirano C, Wu ZQ, Borad MJ, Frantzen M, Roussos E, et al: The proteasome inhibitor PS-341 markedly enhances sensitivity of multiple myeloma tumor cells to chemotherapeutic agents. Clin Cancer Res 9: 1136-1144, 2003.

33. Quinn BA, Dash R, Azab B, Sarkar S, Das SK, Kumar S, Oyesanya RA, Dasgupta S, Dent P, Grant S, et al: Targeting Mcl-1 for the therapy of cancer. Expert Opin Investig Drugs 20: 1397-1411, 2011.

34. Le Gouill S, Podar K, Harousseau JL and Anderson KC: Mcl-1 regulation and its role in multiple myeloma. Cell Cycle 3: $1259-1262,2004$

35. Derenne S, Monia B, Dean NM, Taylor JK, Rapp MJ, Harousseau JL, Bataille R and Amiot M: Antisense strategy shows that $\mathrm{Mcl}-1$ rather than $\mathrm{Bcl}-2$ or $\mathrm{Bcl}-\mathrm{x}(\mathrm{L})$ is an essential survival protein of human myeloma cells. Blood 100: 194-199, 2002.

36. Clohessy JG, Zhuang J, de Boer J, Gil-Gómez G and Brady HJ: Mcl-1 interacts with truncated Bid and inhibits its induction of cytochrome c release and its role in receptor-mediated apoptosis. J Biol Chem 281: 5750-5759, 2006.

37. Craig RW: MCL1 provides a window on the role of the BCL2 family in cell proliferation, differentiation and tumorigenesis. Leukemia 16: 444-454, 2002.

38. Willis SN, Chen L, Dewson G, Wei A, Naik E, Fletcher JI, Adams JM and Huang DC: Proapoptotic Bak is sequestered by Mcl-1 and Bcl-xL, but not Bcl-2, until displaced by BH3-only proteins. Genes Dev 19: 1294-1305, 2005.

39. Chen L, Willis SN, Wei A, Smith BJ, Fletcher JI, Hinds MG, Colman PM, Day CL, Adams JM and Huang DC: Differential targeting of prosurvival $\mathrm{Bcl}-2$ proteins by their $\mathrm{BH} 3$-only ligands allows complementary apoptotic function. Mol Cell 17: 393-403, 2005.

40. Han J, Goldstein LA, Gastman BR and Rabinowich H: Interrelated roles for Mcl-1 and BIM in regulation of TRAIL-mediated mitochondrial apoptosis. J Biol Chem 281: 10153-10163, 2006.

41. Gomez-Bougie P, Bataille R and Amiot M: The imbalance between Bim and Mcl-1 expression controls the survival of human myeloma cells. Eur J Immunol 34: 3156-3164, 2004.

42. Leu JI, Dumont P, Hafey M, Murphy ME and George DL: Mitochondrial p53 activates Bak and causes disruption of a Bak-Mcll complex. Nat Cell Biol 6: 443-450, 2004.

43. Weng C, Li Y, Xu D, Shi Y and Tang H: Specific cleavage of Mcl-1 by caspase-3 in tumor necrosis factor-related apoptosisinducing ligand (TRAIL)-induced apoptosis in Jurkat leukemia T cells. J Biol Chem 280: 10491-10500, 2005. 